\title{
El bipartidismo como contexto del proceso electoral costarricense
}

Trino Barrantes

ste breve esbozo de la coyuntura electoral en Costa Rica se inscribe como parte de un ejercicio intelectual, a fin de contribuir con una lectura más "científica" del tejido social que articule el espectro de la geografia política de Centroamérica.

Se dice que la "democracia es y se concreta en el voto", según el criterio de la mayoria de los ciudadanos costarricenses; nosotros buscaremos desmitificar dicha opinión.

La hipótesis central de este esfuerzo académico busca demostrar que:

Las elecciones del 4 de febrero de 1990 , el triunfo del licenciado Rafael Ángel Calderón Foumier y del Partido Unidad
Social Cristiana, consolidán el bipartidismo como característica fundamental del sistema electoral costarricense; se acentúa el proyecto neoliberal en términos económicos y consecuentemente, se estrechan los límites de la democracia liberal burguesa hacia otras opciones.

PERSPECTIVA ELECTORAL Y CONTINUISMO NEOLIBERAL

El esquema de desarrollo capitalista costarricense, hasta 1975, en vez de excluir más bien incorporó en su seno un conjunto de sectores de clases que son los que le permiten hacer viable un largo proyecto de Estado benefactor y paternalista. 
Este largo periodo caracterizado por un gran contenido socialdemócrata, es resultado de la política del Partido Liberación Nacional (PLN), mismo que comienza a ceder espacios ante el advenimiento del Estado libre-empresario y, más recientemente, a un capitalismo basado -en exclusiva- en el sector privado y la exportación. A finales de la década pasada surge un nuevo bloque de fuerzas, el bloque exportador financiero, que nos descubre fácilmente sus rasgos y nos permite reconocerlo en el interior de los dos partidos mayoritarios, signándoles su especificidad, pero con una clara tendencia a un bipartidismo que tiene sus correspondencias con las tendencias a nivel internacional. Esto porque "el PLN se ha desvivido por parecerse a las socialdemocracias europeas y a los demócratas norteamericanos. Los socialdemocristianos, han emulado mimetizando a sus homólogos italianos y alemanes". 1

Frente a este claro panorama de un solo proyecto económico con dos cabezas visibles a nivel político partidario, la construcción de una tercera opción es casi imposible.

\section{EL BIPARTIDISMO}

Aunque la Constitución política de Costa Rica tenga el precepto de que todo ciudadano puede agruparse en partidos politicos y participar en la campaña, además de las consabidas reformas de 1956 , 1971 y 1972 que atienden a la contribución del Estado para financiar los gastos de los partidos políticos, según lo estipulado en la llamada "deuda política adelantada", la realidad es otra cosa, toda

\footnotetext{
' Jaime Delgado, La República, 27 de diciembre de 1989, p. 17.
}

vez que sólo dos partidos, Liberación Nacional y la Unidad Social Cristiana (USC), se repartieron la casi totalidad de la deuda, cuyo monto no puede ser superior por ley al $2 \%$ del promedio de los presupuestos ordinarios de la República. ${ }^{2}$

Las articulaciones de lo estrictamente electoral no son los aspectos más típicos del bipartidismo. Otros contenidos lo constituyen los acuerdos tácitos en política económica de cara a los organismos financieros internacionales, asi como sus rasgos de política exterior circunscritos a la propuesta de la Casa Blanca, que poco tienen que ver con un país que vende al exterior un nuevo clisé: la democracia centenaria, como un ron que se añeja en los toneles del bipartidismo. En definitiva, hay un cierto desgaste, una especie de "deformación electorera" que, aunque la misma quede avalada cada cuatro años por un buen contingente de votantes, cada vez más están excluidos y limitados de las decisiones y participación estatal.

No pretendemos ni es el objetivo, cercenar la importancia histórica del voto, pero sí podemos consignar y afirmar que el actual esquema democrático de Costa Rica reduce la decisión de las mayorías al simple ejercicio del sufragio.

Dicho porcentaje de votantes no puede distinguir lo real de lo especulativo en la propuesta-ofenta de los partidos mayoritarios y acoge sin ningún reparo los de mejor alcance propagandístico sin

${ }^{2}$ Según indicó el contralor general, Elías Soley, "el presupuesto ordinario de la república para el 87 fue de 40520821000 colones; para el 88 de 52274 823841 y en 89 de 56124800000 haciendo un total de 148920444841 colones y un monto promedio de 49640148280 , cuyo $2 \%$ es de 992802965 colones, limite máximo de contribución del Estado a los partidos políticos" (89 colones por un dólar), La Repüblica, 4 de febrero de 1990, p. 7. 
que necesariamente atiendan a un cambio y mejora de sus demandas.

Con este monopolio de los recursos por parte de ambos y la debilidad de los otros partidos, en ausencia de discusiones programáticas, con una campaña electoral que nos sugiere más bien una excelente articulación y efectiva estrategia publicitaria -en lugar de ampliarse y profundizar la democracia- se lleva la actual coyuntura a un unipartidismo bicéfalo tendencialmente cada vez menos democrático.

Este breve xamen de las propuestas electorales de ambos partidos: PLN-USC, deja claramente establecido sus grandes puntos de coincidencia, o lo que llamamos un monopartidismo económico de dos cabezas políticas. El marco que ofrecemos al respecto ayuda en este sentido a clarificar que los depositarios de este acto de "marketing electoral", siguen siendo las mayorias mientras que los gobiernos mantienen la acción en el escenario durante cuatro años a favor de minorías privilegiadas.

\section{El PARTIDO LIBERACIÓN NACIONAL (PLN)}

El PLN surgió a la luz pública en 1952 , aunque ya en 1940 sus planteamientos ideológicos habían madurado con el Centro de Estudios para los Problemas Nacionales y, posteriormente, con el Partido Acción Democrática. De una clara orientación socialdemócrata impregna durante un largo periodo reformista al Estado costarricense. No es el interés de este trabajo un examen exhaustivo de esta organización sino buscar algunos elementos que expliquen su derrota en la última contienda electoral. Misma que para el PLN en términos históricos, no sólo significó la pérdida del ejecutivo, sino de la Asamblea Legislativa y la ma- yor parte de los municipios, lo cual es muy significativo dada la importancia que estos organismos ienen en el quehacer político costarricense. Veamos esto en cifras:

De un total de 1692050 votantes distribuidos en 7597 mesas electorales, LN obtuvo $47.3 \%$ de votos, o sea 604020 costarricenses sufragaron a favor de la socialdemocracia (cuadro 1). Sin embargo, las provincias tradicionalmente bastiones del "liberacionismo" fueron ganadas por los socialcristianos.

Un examen del padrón electoral (cuadro 2) muestra cierta tendencia y comportamiento geográfico del voto y además nos permite ensayar algunas hipótesis que pudieran demostrar el comportamiento de sectores y algunas de las razones de la derrota del PLN. Señalemos algunos elementos que consideramos importantes:

a) El comportamiento de la juventud. Este sector de población es mayoritario en Costa Rica; el padrón electoral de 1986 (1 486474 votantes) experimentó un drástico aumento de $13.8 \%$ de sufragantes; estos datos demuestran que, de alguna manera, los votantes cuyas edades oscilan entre los 18 y 29 años son casi 600 000; de ellos 300000 votaron por primera vez.

b) Los pequeños agricultores $y$ el sector informal de la economía. Aunque en términos programáticos el PUSC no ofreció respuestas contundentes para la atención de estos sectores, sí ofreció, propagandisticamente hablando, un conjunto de promesas que le posibilitaron la adherencia de dichos sectores. Contribuyó a esta derrota el que el PLN en ocho años consecutivos desatendió a esta masa de población electoral en términos de sus demandas más estructurales. Podríamos argumentar que el "mensaje del PUSC estuvo más dirigido y tuvo

\section{5}

3

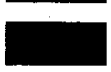




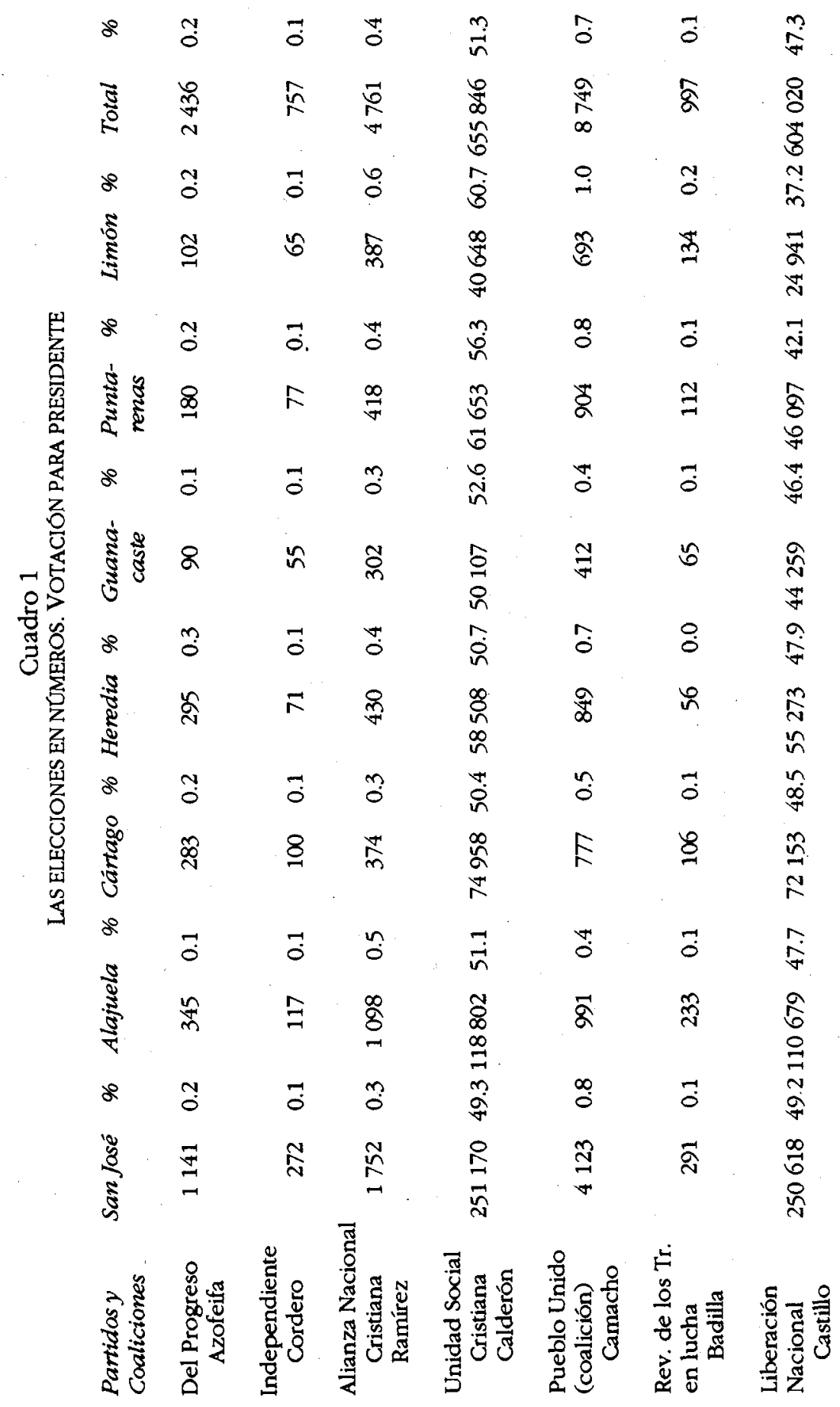


Cuadro 2

PADRON NACIONAL ELECTORAL

Total de electores 1986: 1486474

Total de electores 1990: 1692050

Aumento

$205576=13.82 \%$

Desglose en provincias

$\begin{array}{lrrr}\text { Provincia } & \text { Total } & \text { Hombres } & \text { Mujeres } \\ \text { Costa Rica } & 1692050 & 848728 & 843322 \\ \text { San José } & 665920 & 320815 & 345105 \\ \text { Alajuela } & 296419 & 150546 & 145873 \\ \text { Cartago } & 186969 & 94368 & 92601 \\ \text { Heredia } & 141210 & 69920 & 71290 \\ \text { Guanacaste } & 123981 & 63675 & 60306 \\ \text { Puntarenas } & 163027 & 86854 & 76173 \\ \text { Limón } & 114524 & 62550 & 51974\end{array}$

Fuente: Periódico La Repüblica.

mayor penetración entre clases bajas y de menor nivel educativo". ${ }^{3}$

c) Desarticulación de estructuras internas, narcotráfico y corrupción. El PLN no logró una oxigenación de sus estructuras internas después de la convención del 19 de febrero de 1989 y el doctor Carlos Manuel Castillo tampoco estuvo a la altura de darle la cohesión que dicha organización necesitaba. Conjuntamente con estos aspectos el PUSC orquestó una gran campaña contra el narcotráfico y la corrupción en el gobiemo de Oscar Arias, haciendo una simetría, que resultó a los ojos del electorado, fácil de identificar con el PLN.

d) ¿Alternancia en el poder o dictadura de partido? Este argumento, usado como eslogan por el PUSC -pese a su inconsistencia teórica-contribuyó decididamente a ganar un espacio electoral a este partido. Le llamamos inconsistencia

${ }^{3}$ Periódico La nación, 6 de febrero de 1990 , p. 8. porque como se ha demostrado en los párrafos anteriores no existen puntos de ruptura en lo sustancial, en la propuesta programática de ambos partidos. Empero como recurso del "marketing electoral" demostró su indiscutible efectividad simbólica.

e) Contenido neoliberal del PLN. Otro elemento que debe tenerse presente es la percepción de que, en el actual gobierno de Arias, hay cierto dislocamiento en la ejecución de las tesis socialdemócratas; según un editorialista del periódico La República "resulta el gobierno liberacionista más antiliberacionista de la historia del PLN". "Este señalamiento ha tenido costos político-electorales contundentes para el doctor Carlos Manuel Castillo por parte del sector más genuino de la socialdemocracia liberacionista.

Señalamos así los rasgos más visibles y coyunturales de la derrota del PLN; ló-

\footnotetext{
- Alberto Franco Cao, La Prensa Libre, 7 de febrero de 1990.
}

\section{5}


gicamente los aspectos de orden estructural requeririan de un examen y una lectura mas profunda.

\section{El Partido Unidad Social Cristiana}

Al licenciado Rafael A. Calderón Fournier, presidente electo de Costa Rica, se le debe en parte la compactación de la unidad opositora. En cuanto al PUSC, organización surgida a partir de 1983 y resultado de una coalición de cuatro partidos políticos: Democracia Cristiana, Renovación Democrática, Partido Republicano Nacional y Partido Unificación Nacional, sigue sin definir su verdadero entorno ideológico, aunque comienza a lograr, efectivamente, su proceso de despersonalización y de mayor nivel institucional. $^{5}$

Metodológicamente hablando, sería incorrecto y poco objetivo resolver por analogía al PLN el análisis del triunfo del PUSC a partir de sus debilidades analizadas, ya que hemos mantenido como hilo conductor y como preocupación teórica en este trabajo el peso de los signos externos y las formas concretas en la manipulación de la conciencia electoral del costarricense, mismos que serán analizados en el capítulo siguiente. ${ }^{6}$

De estos signos externos y símbolos publicitarios derivamos que las promesas electorales del pUSC y el contenido económico, social y político del "programa electoral" (véase cuadro 3), tuvie-

\footnotetext{
${ }^{5} S$ e hace referencia a la despersonalización del puscpor parte de La Nación, 6 de febrero de 1990 , p. 14 .

${ }^{6}$ Ailes Roger, asesor norteamericano del pusc, contribuye a fortalecer este argumento cuando al referirse a Rafael A. Calderón, sostiene que fue mejor candidato y el pusc tuvo mejor organización, soporte económico y buen asesoramiento, La Nación, 11 de febrero de 1990, p. 11.
}

ron una magnificación que estuvo legitimada por el electorado en la pasada contienda, independientemente de la configuración sectorial con la cual se articuló dicho partido político. ${ }^{7}$

Considerado de esta manera el mapa político de estas dos fuerzas mayoritarias en su comportamiento electoral, nos surgen algunas preguntas: ¿es posible, en las actuales condiciones, un gobiemo de consenso en el nuevo proyecto socialcristiano? ¿Está el nuevo gobierno en capacidad de reestructurar las relaciones Estados-sociedad? ¿Amplía este nuevo "triunfo de la oposición" a la democracia costarricense? Estas son algunas de las interrogantes que pretendemos dilucidar de alguna manera en este trabajo. Sin embargo la inmediatez de la coyuntura que está siendo analizada no nos permite ensayar respuestas contundentes. La prueba del llamado "perfeccionamiento democrático" no puede atender a dos contenidos "políticoprogramáticos" disímiles en sus argumentos y necesidades. Un sector minoritario cada vez más neoliberal (llámese PUSC o PLN) y una masa electoral más urgida de resolución de sus promesas.

\section{MARCO ECONÓMICOY PROPUESTA PARTIDISTA}

Desde 1983, con el Plan de Ajuste Estructural I (PAE I), nuestro país inició un proceso de modernización de la administración pública, o mejor dicho de privatización de servicios e instituciones,

\footnotetext{
${ }^{7}$ En la separata de la revista costarricense Aportes de febrero de 1990 se señala que "en la medida en que elfuturo gobierno intente honrar sus deudas con los electores sobre la base de medidas de reforma social, se enfrentará a las políticas del Fondo Monetario Internacional y quizas a poderosos intereses dentro del partido", p. 2.
} 


\section{Partido pusc}

\section{Política económica:}

-Desconcentración y descentralización del Estado.

-Revisión y fortalecimiento del régimen municipal.

-Impulsar nuevos programas de ajuste estructural, con el apoyo del FMI y del Banco Mundial.

-Drástica contención del gasto público.

- Mejoramiento de la recaudación fiscal.

-Estudio permanente de incentivos de la producción.

-Menores y más espaciadas minidevaluaciones según tasa de inflación.

-Negociación de deuda externa mediante su recompra, reconversión o condonación.

-Reactivación del Mercado Común Centroamericano

- Generar mayor valor agregado.

-Nuevo plan de fomento bananero para exportar 100 millones de cajas anuales. - Lograr autosuficiencia en producción de arroz, frijol y maíz. Mejorar programas lecheros y superar la crisis de ganado de carne. -Mayor impulso al turismo.

Politica social:

- Creación del Instituto para la Familia.

- Reformas a planes sanitarios y de vivienda.

- Crear nuevas fuentes de empleo.

- Creación de las procuradurías de la mujer y contra la corrupción.

\section{Política exterior}

-Apoyo al proceso de Esquipulas II.

-Respetodelos principios de no intervención. Autodeterminación y no uso de la fuerza. Salvo en legítima defensa. Con base en los postulados del TIAR.

-Fortalecimiento de la OEA.

-Activa participación en la defensa de los derechos Humanos.

\section{Partido PLN}

\section{Política económica:}

-Economía al servicio del hombre, mediante un desarrollo que promueva la justicia social.

-Economía mixta bajo un mercado libre con participación del Estado.

-Incremento de la producción nacional con un creciente apoyo de nuevas formas de producción asociativa.

-Producción orientada a la exportación para insertarse con mayor fuerza en el mercado internacional. Aunque sin la acción en el Mercado Común Centroamericano.

-Mantener programas de ajuste estructural.

-Redefinición del intervencionismo del Estado en la economía incentivar la reconversión agroindustrial con fines exportadores.

\section{Politica social:}

-Creación de Centros de Atención Integral del Niños.

-Transporte gratuito para ancianos y estudiantes.

-Aguinaldo adicional en febrero para compras de útiles y uniformes escolares.

-Mantener programas sociales de salud, vivienda y atención de niños minusválidos y personas de la tercera edad.

-Generación de nuevos empleos. Especialmente para la juventud.

-Política de salarios crecientes.

-Estricto control de precios de la canasta básica.

\section{Politica exterior:}

-Política exterior basada en la lucha por los derechos humanos y el apoyo a la democracia.

-Proseguir con la política de paz marcada por el mandatario Oscar Arias.

-Costa Rica como principal promotor de paz en el conflicto regional.

-Fortalecer alianza con naciones democráticas frente a las dictaduras.

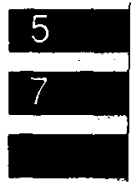


con un marcado rumbo y orientación a la desnacionalización y desmantelamiento del Estado. ${ }^{8}$

El contexto económico en que tiene lugar este proceso electoral determina el curso del gobierno socialcristiano para el próximo cuatrienio. Ni el PLN ni el PUSC ofrecieron modelos de recambio o nuevas opciones políticas de reorientación del Estado, ambos habían convenido con el compromiso de ejecutar el PAEIII, idea que contó con el beneplácito de ambos candidatos: Carlos Manuel Castillo y Rafael A. Calderón, además del respaldo expreso de la empresa privada.

Costa Rica ingresó desde 1983 al proceso de "modernización y. privatización" de su economía resultado de los planes de ajuste estructural I y II, cuya sintesis ofrecemos.

PAE: Se aplicó entre 1984 y 1985 , sustentado en un financiamiento de 80 millones de dólares provenientes del Banco Mundial, con el objetivo de establecer un nuevo esquema de desarrollo, diferente del modelo de sustitución de importaciones.

Como resultado, el país experimentó el crecimiento y la diversificación de las exportaciones, al tiempo que contó con disponibilidad de recursos para hacer frente a la balanza de pagos.

PAE II: Comprende el periodo 1987-90 y el suministro de 200 millones de dólares por parte del Banco Mundial y el gobierno de Japón ( $50 \%$ cada uno).

Sus principales medidas están orientadas a mejorar la eficiencia y produc-

${ }^{8}$ El proyecto neoliberal que sigue el modelo económicocostarricense está avaladopor el nuevo gobierno recién electo. Así, Víctor Emilio Herrera, seguidor del pusc y presidente de la Unión de Cámaras y Asociaciones de Empresa Privada-UCAEP manifiesta el apoyo a la aprobación de un nuevo PAE III cuya orientación debe dirigirse a "pasar los impuestos de la producción a la riqueza y el consumo", La Nación, lunes 29 de enero de 1990 , p. 8. tividad de las actividades nacionales para competir con éxito en terceros obstáculos que impiden a los empresarios hacer un uso más rentable de los recursos del país.

Entre otros aspectos, estipula la modernización del sistema financiero, la reducción del desequilibrio en las finanzas públicas, la disminución de aranceles a los bienes importados y la programación de la inversión estatal.

La Nación, 29 de enero de 1990.

Si las estadisticas oficiales demuestran que el país ha mantenido una década llamada de "estabilidad con crecimiento", con un relativo crecimiento del sector agropecuario y una tasa de desempleo que parece haberse estacionado, cabe entonces iniciar con una suerte de preocupación teórica para encontrar los factores que llevaron a la derrota del PLN.

La ausencia de los sectores populares en las políticas estatales, una población actual calculada en más de 700000 personas en estado de pobreza, ${ }^{9}$ el problema irresuelto de los tugurios y otros rasgos visibles, ${ }^{10}$ sirven de indicadores generales para el PUSC en su reciente triunfo electoral.

Los límites de la dimensión social de la política gubernamental en los aspectos sustanciales como vivienda, salud, educación, seguridad de bienes y perso-

${ }^{9} \mathrm{La}$ Nación, 5 de febrero de 1990, p. 22; también se recomienda para el análisis de estos datos $L a$ República, 11 de febrero de 1990 , p. 6.

${ }^{10}$ Además de los datos ofrecidos, la causa básica de estos problemas tienen como consecuencia la expansión de la privatización de la economía, con un sector público, considerado por diversos analistas, distorsionador de la producción y profundamente desequilibrador de las finanzas, La Nación, 7 de febrero de 1990, p. 14 .

Por otra parte el proteccionismo industrial financiero y agrícola no logró captar el apoyo de los sectores a los cuales va dirigido a saber, el pequeño campesino y el pequeño industrial, $L a$ Repüblica, 11 de febrero de 1990, p. 6. 
nas, estabilidad laboral, salario, etc., volcaron a una gran masa de electores a favor del PUSC, el cual ofreció al Estado como cuerno de la abundancia en términos de la promesa electoral ofrecida al pueblo costarricense.

Detrás de estos ámbitos sociales específicos, el apoyo del pequeño productor de la zona rural, grandes masas urbanas empobrecidas, un contingente de población desocupada, refrendan con su voto al proyecto del pusc. ${ }^{11}$

La atención de las promesas electorales como compromiso asumido por el recién electo presidente de la república, no sólo requerirán de un claro contenido económico, exigen profundas modificaciones estructurales del Estado costarricense, aspecto que sin lugar a dudas no podrá llevarse a cabo por el carácter neoliberal que avecina el nuevo gobierno. ${ }^{12}$ Pareciera que los principios técnicos adoptados conjuntamente por las dos

11 "El voto que nos hizo ganar estuvo basado en la esperanza, en la modificación de algunas políticas que estaban creando una mayor brecha social y perjudicando a las clases más desposeidas de este país. Ese es el compromiso mâs grande que hemos adquirido en estas elecciones. Pienso que el próximo gobierno tiene que revisar la asignación de recursos, las prioridades que se han establecido en administraciones anteriores y, por supuesto, las medidas que se tomen no pueden perjudicar la producción nacional, porque si ésta no crece no tendremos de dónde mejorar las condiciones de esas clases más pobres, pero sí tenemos que establecer prioridades sobre las necesidades para destinar recursos de los existentes en el Estado, sin que esto signifique nuevos impuestos al sector productivo." Germán Serrato Pinto, primer vicepresidente electo del Pusc, $L a R e$ pública, 9 de febrero de 1990, p. 14.

${ }^{12}$ Para el editorialista del periódico La Nación "este grito social no se aplicará, sin embargo, con simples correctivos o cataplasmas, o con planes estatales impulsados por el sentimiento, sino mediante una acción global concertada del Estado y la iniciativa privada ${ }^{n}$, La Nación, 8 de febrero de 1990 , p. 14. fracciones parlamentarias en el actual gobierno, no se modificarán; por el contrario perpetuarán cierto tipo de Estado neoliberal envuelto en una doble vía. ${ }^{13}$

El pueblo se jugó la carta del "cambio" pero con su voto se acentuó el bipartidismo; la democracia -al menos en la visión electoral- estrechará cada vez más sus límites y deslegitimará sus propios contenidos.

\section{SIGNOS EXTERNOS Y COMPORTAMIENTO DEL VOTO}

Si el espacio donde se legitima (per se) el sistema está mediado objetivamente por lo político-electoral en tanto que, al menos formalmente, todos podemos elegir, ¿qué legitima a la democracia costarricense frente a un discurso neoconservador por parte de los dos partidos mayoritarios?, ¿se ha elegido a un equipo nuevo y de más claros enfoques?, ¿se recupera el concepto de nación y se inscribe el ofrecimiento de la política social del nuevo gobierno hacia una atención integral de los sectores subal-

${ }^{13}$ "Si recordamos que en materia económica el país está regido por el llamado plan de ajuste estructural, y que esta estrategia ha sido aprobada en el parlamento con los votos del PLN y del PUSC, seguramente habrá que deducir que no habrá sorpresas. Lo novedoso puede ser el compromiso adquirido por don Rafael Ángel Calderón con los sectores populares y marginados, promesas que para concretarse necèsitarian una revisión de los postulados neoliberales implícitos en el plan de ajuste estructural; en este punto deberá resolverse una de las principales incógnitas que rodean al próximo gobierno, el enfrentamiento entre un influyente y duro sector oligárquico, férreamente adherido a las fórmulas fondomonetaristas, y otro sector no despreciable que parece encabezar el vicepresidente electo Serrano Pinto, que abogaría por seguir creciendo en el marco del plan de ajuste estructural pero repartiendo con una opción de justicia social", Libertad, 8 de febrero de 1990, p. 4.

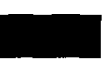


ternos?, ¿por qué contenidos programáticos votaron los costarricenses el 4 de febrero?

Dos estrategias de lenguaje pueden encontrarse para dar respuesta a lo anterior; ${ }^{14}$ la que sitúa un esquema maniqueísta del discurso entre lo democrático y lo comunista, este último por supuesto, como portador de la desestabilización. El otro tipo de argumentación es el que sostiene que el costarricense es portador histórico de una conciencia democrática. ${ }^{15}$

14 "En la ofensiva neoconservadora en torno a los valores no políticos (la familia, la religión, el civismo, la disciplina, el sacrificio), cuyo objetivo es precisamente que el individuo se aleje de to material (que no pida aumentos salariales, tierra para sembrar, vivienda) y se refugie en lo espiritual", Willy Soto A., Ideología de la violación de los derechos bumanos, CODEHU, San José, 1987.

15 "En mi opinión los costarricenses vivimos inmersos en una sociedad civil cuya identidad se
Ambas aproximaciones, aunque separadas teórica y conceptualmente, nos ayudan a fijar los vértices en el rectángulo electoral. Lo que se jugó en Costa Rica en el último proceso electoral, como se mencionó anteriormente, no fue precisamente el fortalecimiento de la democracia, por el contrario, se afinaron los mecanismos de angostamiento y sus propios límites. Con la exclusión de las "opciones" minoritarias mediante un

basa en cinco datos de nuestra conciencia democrática: exigimos respeto a las libertades dentro de sus límites morales; creemos en la vigencia de los derechos humanos y la justicia; tenemos estricto apego a la Constitución y las leyes; experimentamos en este acto un vivo sentimiento de solidaridad colectiva, y cumplimos con un deber de lealtad a la patria. Por eso digo que al votar sin siquiera darnos cuenta de estos cinco principios, estamos votando por el aire que respiramos", Azofeifa, 1990.

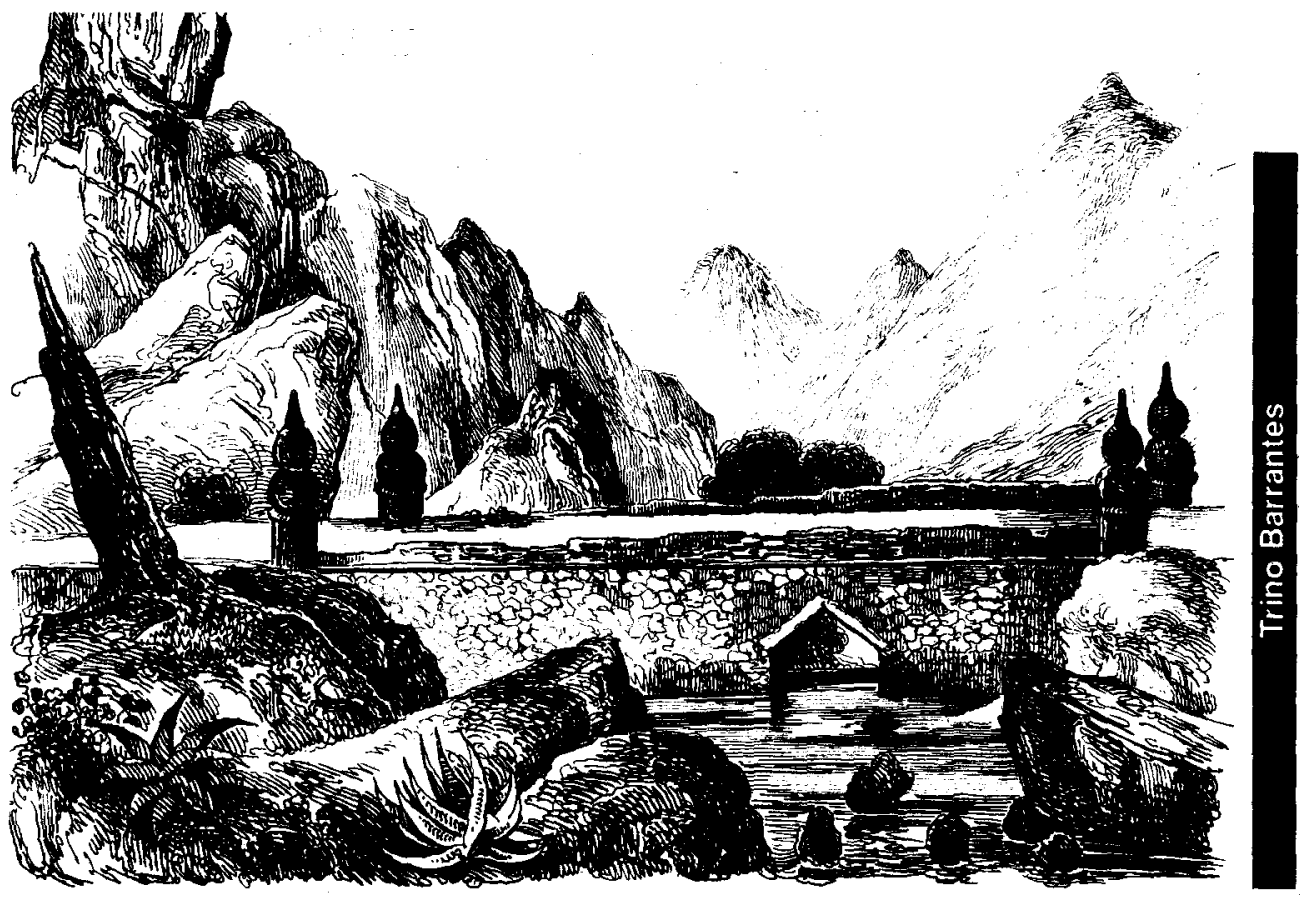


juego antidemocrático de reparto de la deuda política, se desdice y desdibuja mucho de lo "centenario" que tiene el mito democrático y, a la vez, fortalece el bipartidismo.

Lo cierto de esta campaña millonaria es que no ofreció, una vez más, ningún tipo de discusión programática, sino un conjunto de promesas, engaños y mentiras. Con ello uno de los beneficiarios del bipartidismo, el PLN, se convirtió en el gran perdedor. Joe Napolitan, asesor norteamericano de la campaña del doctor Carlos Manuel Castillo, aseguró que aún a finales de noviembre de 1989 el PLN estaba en problemas por la orientación de su campaña y publicidad. En el mismo rotativo se ofrecen las recomendaciones secretas de Joe Napolitan al doctor Castillo. Leamos al respecto:

\section{Definir una estrategia.}

2. El mando de la campaña es inteligente y competente. Su debilidad es la falta de experiencia. Eso puede corregirse incorporando gente que tiene esa experiencia.

3. Encuentro a Castillo inteligente y atractivo, pero en televisión aparece como un burócrata aburrido. Compárese lo que se hizo con Oscar Arias y las diferencias aparecerán rápidamente.

4. Corríjase el hecho de que no existen líneas claras de autoridad en la campaña.

5. Desarróllese una lucha agresiva para recaudar dinero. No es posible ganar si no se recaudan amplias sumas.

6. Buena gente del PIN no ha sido usada. Ese fue un error en los comienzos de la campaña de Oscar Arias. Cuando se corrigió la campaña floreció.

7. Definase una campaña para atacar a Calderón. Lo único negativo que he oído es su vínculo pasado con Carazo. Pero fue hace ocho años. Hay $200000 \circ 400000$ nuevos votantes desde ese tiempo. Debe haber otros puntos negativos. ${ }^{16}$

${ }^{16}$ La Nación, 11 de febrero de 1990 , p. 5.
Los problemas del PLN no son resultado exclusivo de la campaña electoral. Desde el 19 de febrero de 1989 el partido signó parte de su derrota, de alguna manera, al descubrir puntos muy susceptibles y vulnerables a la crítica de la opinión pública. Pero la crisis moral del pLN, a decir verdad, no descubrió su verdadero magma de significaciones reales. Por otra parte, la convención de la USC tampoco ofreció ninguna garantía democrática, a no ser su esquema propagandístico de ofrecimientos y promesas.

Si el bipartidismo encuentra sus cauces de afirmación en parte gracias al apoyo de la deuda política adelantada, lo que objetivamente niega un proceso de verdadero pluralismo, no es éste el mejor indicador de la debilidad de los partidos minoritarios, en especial de la izquierda tradicional que reclama para sí su patente de corso de tercera opción. Factores más estructurales, tales como su escasa percepción de la coyuntura, su lectura poco objetiva de los nuevos sujetos sociales y su ausencia programática, son las causas básicas para disputar espacios al bipartidismo. A esto hay que añadir dos hechos concomitantes: $a$ ) que algunos partidos siguen aferrados a un papel de representación testimonial o simbólica, una especie de "adorno de la democracia", que termina por legitimar el bipartidismo real, y b) que algunos "dirigentes" de esos partidos minoritarios no tienen más motivación que su propio ascenso a posiciones de prestigio. Su "proyecto" se agota en su propia candidatura.

Y como si todo esto fuera poco, muchos ciudadanos respetables, inconformes con el bipartidismo, con un liderazgo real aunque sea inorgánico, con condiciones personales y objetivas para prestarle preciosos servicios al país posponen sus responsabilidades patrióti-
6

1

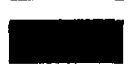


cas a su prestigio, sus prejuicios, su comodidad o a su "a mi no me toca". Prefieren que sean otros los que se echen a la calle, los que corran los primeros y mayores riesgos, los que sorteen a los primeros aliados $y$, en definitiva, se quemen.

Reiteramos, en una campaña caracterizada por la ausencia de planteamientos programáticos, con cierta modalidad antidemocrática de distribución de recursos, es imposible, o casi, la construcción de terceras opciones. Una campaña que se montó sobre el "modelo made in USA" de impacto de las imágenes de los candidatos y de eficiencia de las maquinarias electorales ${ }^{17}$ lógicamente tenía que ofrecer el comportamiento electoral ya conocido. Los paliativos de las promesas de campaña (cuadro 4) a compañados de una bien orquestada campaña de signos externos (cuadro 5) tocaron la sensibilidad del votante que apostó a favor de "una paz con justicia social" y al ofrecimiento populista del bono familiar gratuito.

Con base en todo lo anterior podemos explicarnos por qué $51.3 \%$ de la pobla-

${ }^{17}$ Si Joe Napolitan ha sido meridianamente puntual en el señalamiento de los errores del PLN más preciso resulta Roger Ailes, asesor del PUSC: "No hay ninguna magia, sólo el trabajo arduo", dijo durante una entrevista exclusiva que concedió a La Nación, antenoche, en la suite del hotel Herradura, donde los lideres socialcristianos celebraban los primeros resultados de los comicios.

Estimó, además, que el traspié del pLN no puede catalogarse comouna derrota, pues lo que sucedió fue que el pusc propuso al "mejor candidato" y contó con otros elementos a su favor.

Su visita a Costa Rica se consideró imposible durante varios meses, toda vez que prefirió mantenerse al margen de los fuegos electorales. Incluso, en unas dos oportunidades el licenciado Calderón tuvo que reunirse con él en Estados Unidos.

Sobre este particular es recomendable el análisis que ofrece el semanario Libertad, 8 de febrero 1990. ción electoral se adhirió al proyecto del PUSC, o sea una masa de votantes de 656282 ciudadanos, adverso a las políticas de ocho años de gobierno, conducidas de la mano por los impulsos del ajuste estructural y los compromisos financieros internacionales. ${ }^{18} \mathrm{Las}$ concentraciones de población urbana más empobrecidas, la desatención de las tres provincias periféricas, Puntarenas, Guanacaste y Limón (véase gráfica 1) integrada por un porcentaje muy elevado de campesinado pobre y un representativo contingente del sector informal, empleados de bajos ingresos y desempleados, y básicamente un gran contingente de población joven, son sin duda los factores que definieron el contexto geográfico y social del com-portamiento de los votos que dieron el triunfo al PUSC.

\section{LA IZQUIERDA EN LAS ELECCIONES DE 1990}

El reciente proceso electoral descubrió una serie de aspectos sustanciales del debilitamiento orgánico de la izquierda tradicional, su escasa inserción en las masas, su anacrónico sentido de partido y su anquilosada lectura de la realidad costarricense e internacional.

Nuestra izquierda sigue siendo devota del régimen democrático liberal:

la democracia para ella tiene un valor sustantivo que trasciende clases y que ofrece amplias opciones de vida y participación para el pueblo. Esto se evidencia en un sinnúmero de expresiones de los actuales dirigentes de la izquierda tradicional que señalan que variarán sus métodos y formas de lucha sólo si se les cie-

18 "Elecciones de 1990: los más pobres castigan a Liberación", Aportes, febrero de 1990. 


\section{Cuadro 4 \\ LAS PROMESAS DE CAMPAÑA}

Rafael Ángel Caldenón: Bono familiar gratuito para la vivienda; reparto de las ganancias de las empresas entre los trabajadores; reanudación de la siembra de banano en la zona sur; reconstrucción de la carretera Interamericana; guarderias infantiles para las madres trabajadoras; lucha contra la corrupción y el narcotráfico; creación de más fuentes de empleo; establecimiento del Instituto de la Familia; mejores condiciones para estudiantes y agricultores.

Carlos Manuel Castillo: Construcción de 10000 kilómetros de caminos; 500 guarderías y 60 CEN-CINAI; 160000 viviendas; 83 canchas de futbol; entrega de aparatos de línea blanca para 25 mil familias; aguinaldo escolar para 200000 estudiantes; acueductos rurales; polideportivo para Limón; titulación para 29060 campesinos; transporte gratis para estudiantes; teléfonos y electricidad para 300 comunidades.

\section{Cuadro 5 \\ MENSAJES CIFRADOS}

1. Costo total de la campaña: 1700 millones.

2. Costo de la campaña para el PUSC: 500 millones.

3. Costo de la campaña para el PLN: 550 millones.

4. Gastos de campaña no reportados por los partidos mayoritarios: 650 millones.

5. Número total de anuncios y documentales para televisión elaborados por el Pusc y el PLN: 193 ( 105 el PLN y 88 el PUSC).

6. Número total de anuncios para periódicos elaborados por el PUSC y el PLN: 249 (145 el PLN y 104 el PUSC).

7. Número total de anuncios para radio elaborados por el PUSC y el PL.N: 170 (120 el PLN y 50 el pusc).

8. Número de vehículos que empleará hoy el PLN: 13630 (autobuses y vehículos livianos).

9. Número de vehículos que empleará hoy el PUSC: 20000.

10. Número de guías que utilizará este día el PLN: 103000.

11. Número de guías que utilizará este día el Pusc: 140000 .

12. Número de fiscales de mesa que emplearán los partidos mayoritarios: 5064.

13. Número de personas que utilizará el PLN en su programa "Gane su mesa": 30388.

14. Número de fiscales generales de mesa que utilizará el PLN: 2532.

15. Número de costarricenses que laborarán en la organización de los partidos mayoritarios durante este día: $\mathbf{4 0 0} 000$.

Fuente: voceros autorizados del Pusc y del PIN, en La Nación, 4 de febrero de 1990. 


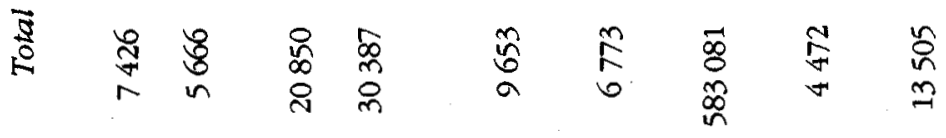

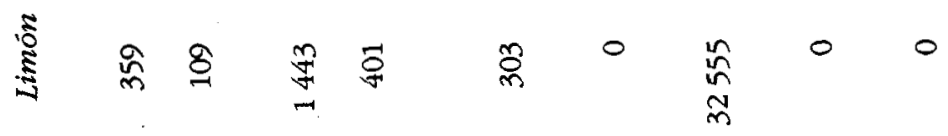

हैं

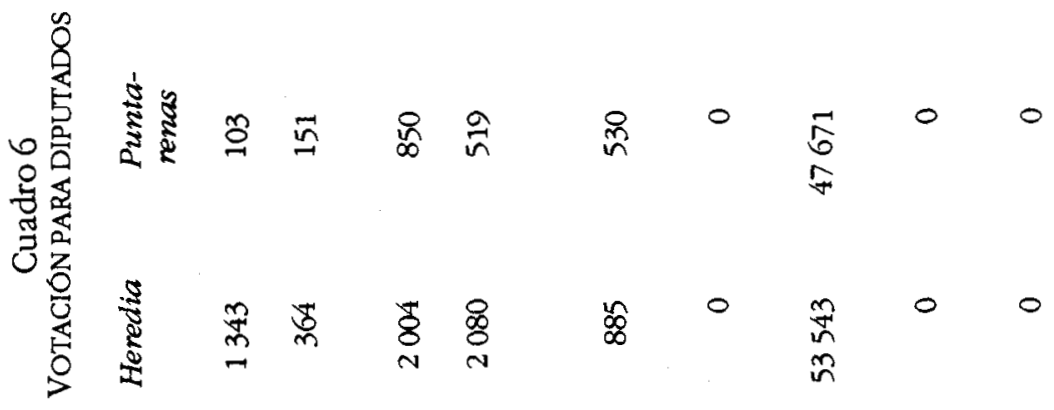

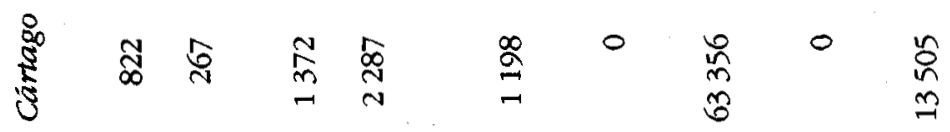

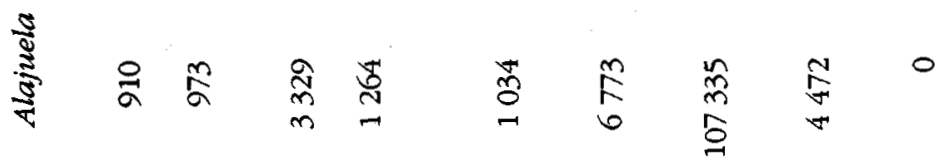

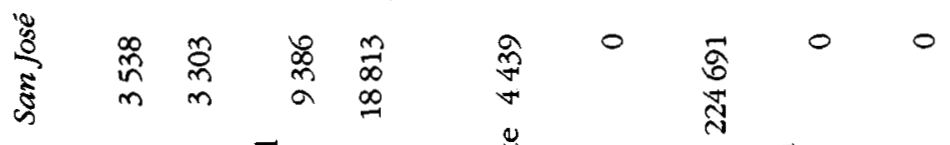

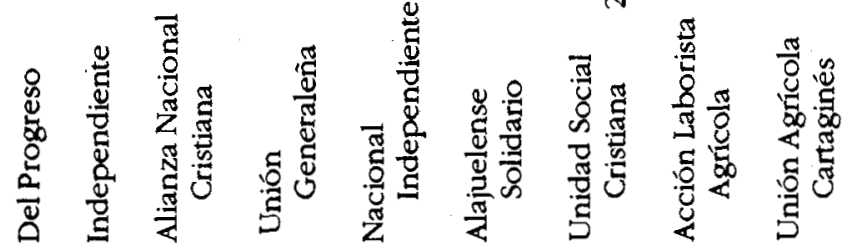




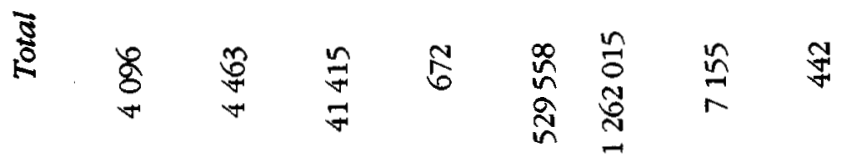

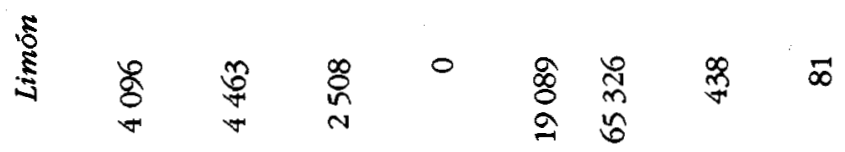

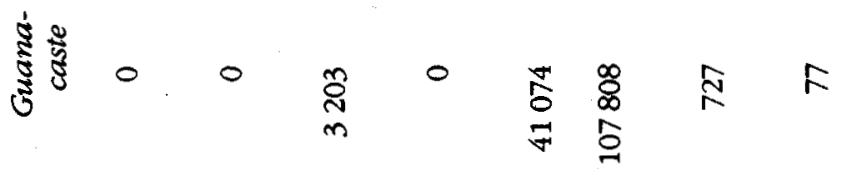

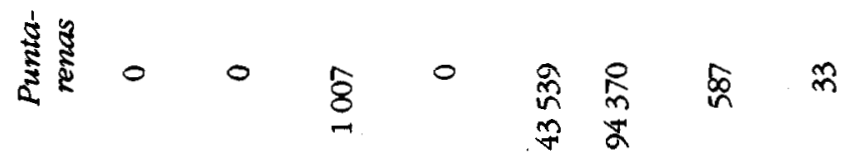

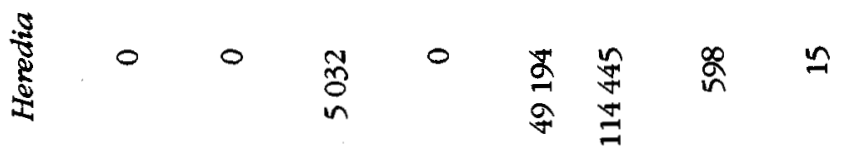

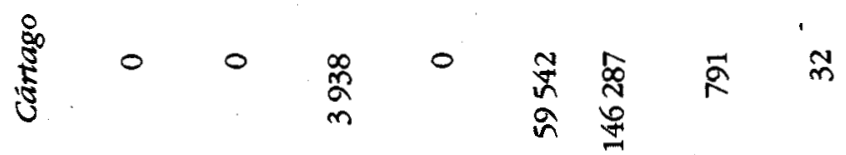

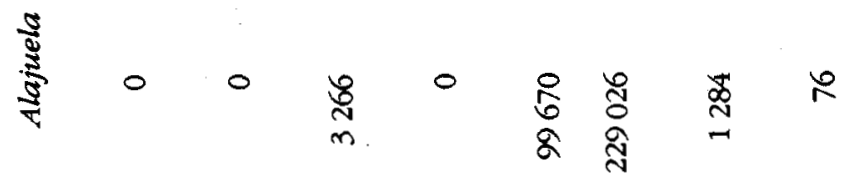

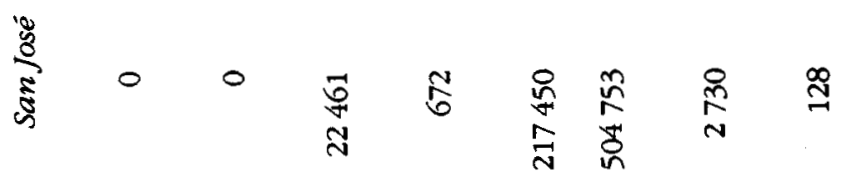

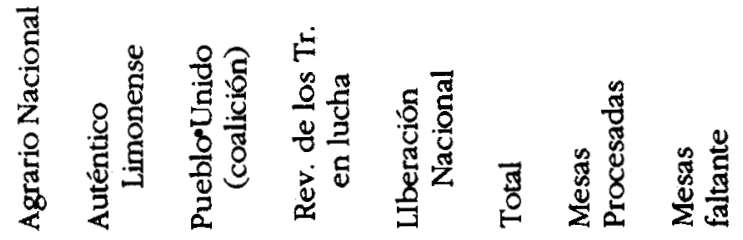




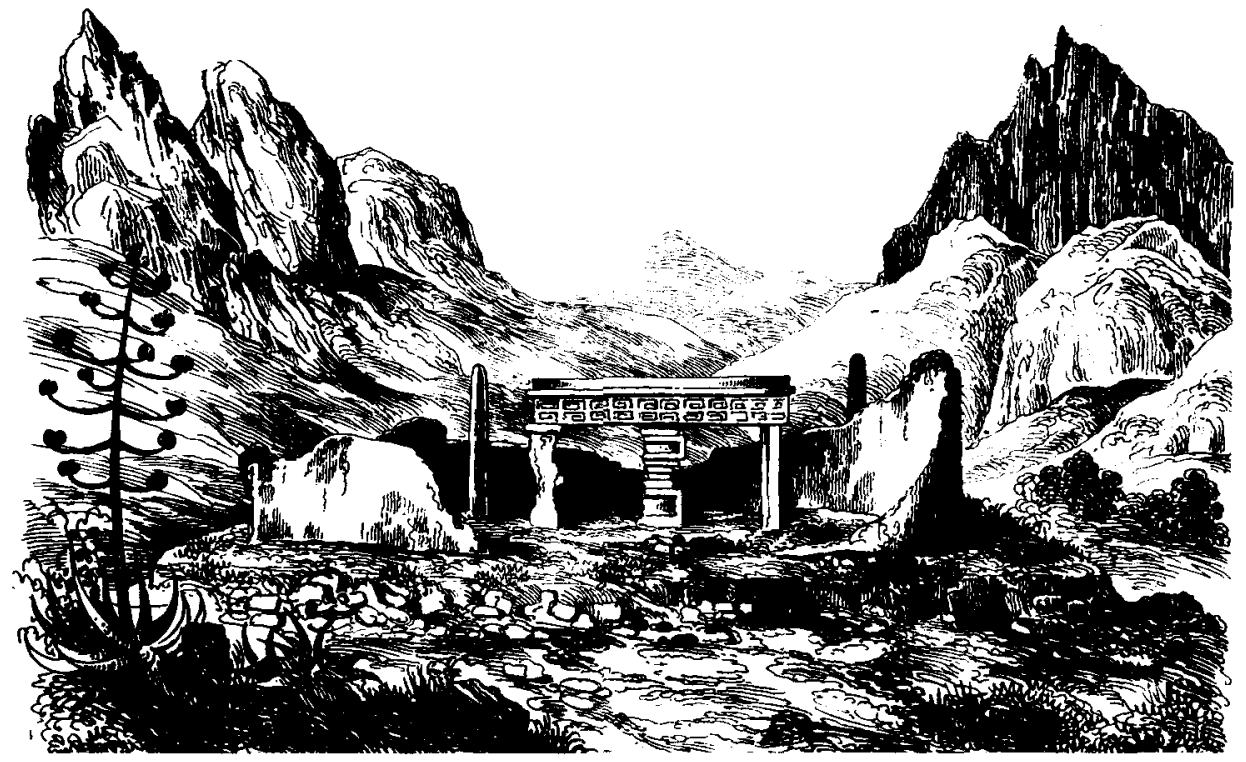

ma el espacio electoral. ... Así, uno de los más grandes y más exitosos logros de la burguesía nacional es el haber establecido un consenso - con el concurso de la izquierda tradicional- de que las elecciones son el acto de mayor protagonismo del pueblo. ${ }^{n 19}$

En este marco la izquierda ortodoxa (y otra que supone no serlo) coaligada en Pueblo Unido, el Partido del Progreso y el Partido Revolucionario de los Trabajadores (PRT), terminan por legitimar lo electoral como el espacio único y ex-

${ }^{19}$ Para reafirmar lo anterior insertamos la cita siguiente que dice: "Costa Rica es una democracia de cien años porque desde hace cien años se celebran elecciones en Costa Rica (hipotéticamente). Esta noción ha creado un gran daño a los costarricenses porque ha restringido la noción de democracia a algo absolutamente técnico y formal: 'la fiesta electoral'." Son importantes para enriquecer el análisis en este particular los aportes ofrecidos en la separata del CIAP: "La comunidad frente a las elecciones de $1990^{n}$, abril de 1989 , San José, y el artículo citado de la revista Tribuna Económica, 1989. clusivo. Refrendan al voto como un "concepto-valor" por encima del contenido clasista, en donde el ejercicio del mismo, perpetúa la democracia. ${ }^{20}$

Ciertamente, la izquierda tradicional se ha dogmatizado y ha convertido en principio estratégico el espacio electoral. No obstante, dicha valoración no tiene correspondencia con la lógica que muestra el proceso. El escaso arraigo popular de la izquierda y, más que ello, los resultados de la última campaña electoral (véanse gráficas 2 y 3 y cuadro 4 ) reflejan tendencialmente lo que venimos señalando. Pero debemos ser más críti$\cos$.

20 "Actualmente hay, sin duda, una tendencia en muchos sectores de izquierda a considerar que la democracia es una categoria exclusivamente 'política' en el sentido más restringido y liberal del término, que en última instancia remite a cierto tipo de relación entre el estado y la 'sociedad civil', relación que se caracterizaría fundamentalmente por la libertad de expresión en abstracto, el pluripartidismo, la realización periódica de elecciones y la observancia de las normas previstas en los respectivos cuerpos legales." 
La escasa votación y la poca adherencia a la propuesta electoral de la izquierda significan, por decirlo de alguna manera, la parte más visible del fenómeno. Lo esencial del mismo no se trasluce, aunque descubre los vértices del agotamiento de la izquierda nacional. Pueblo Unido, el Partido del Progreso y el PRT son, de manera general, la manifestación de un proyecto político desgastado en sus aspectos y planteamientos programáticos fundamentales, en fin, una izquierda acostumbrada en exclusiva a la lucha reivindicativa, con menosprecio de la lucha política y organizativa de más largo alcance, y donde el espacio vital de su concertación política ha estado definido, en los últimos años, por lo electoral. El desprecio a "ultranza" de los nuevos sujetos históricos y de sus masas protagónicas, tales como el movimiento campesino, los ecologistas, la Iglesia popular, son los ángulos menos visibles, pero más estructurales, que sirven de base a la explicación del fracaso de la izquierda costarricense.

Seríamos miopes también si desconociéramos que las modificaciones estructurales del socialismo de la Europa del este, orientado en gran medida a consolidar el programa de las democracias obreras, también tuvo su propio espacio de significación en la derrota de la izquierda tradicional costarricense.

Este "concepto-valor" del espacio electoral ha llevado a la izquierda a participar del último torneo electoral, aun por encima de los obstáculos y límites que el proceso mismo le ofrecía. ${ }^{21}$

Lo anterior nos demuestra la superficial reflexión teórico-metodológica de

21 "Pero, su error principal no sólo deriva dé querer participar a ultranza en la contienda electoral, sino de una lectura de la realidad que nubla lo particular del actual momento político y que los la realidad social de la izquierda, su escaso balance de las condiciones y su precipitado activismo electoral, cuyos resultados han sido muy desfavorables.

Finalmente, la visión cortoplacista, la valoración simplista del tejido social y electoral, y la escasa percepción de los nuevos protagonistas sociales nos señalan un marcado proceso de esclerotización en el análisis por parte de la dirigencia. La superación de la naturaleza ideológica, social y política que configuran el espectro político de la izquierda nacional se convierte en un llamado más que de auxilio; es una urgencia histórica que, obligatoriamente, exige una nueva lectura de la realidad costarricense.

Creemos, al menos por ahora, en dos espacios de construcción obligatoria: a) fortalecer la unidad de las opciones minoritarias con miras a construir la tercera opción, no sólo superando la identidad de lo reivindicativo-electoral, sino dimensionando lo político, vertebrando al pueblo en su verdadero cauce de sujeto histórico. La construcciōn de los centros de contrapoder hegemónico, autogestionarios y autónomos deben revitalizar la orientación del nuevo proyecto para enfrentar el bipartidismo; $b$ ) llevar a cabo un trabajo frentista que supere las anquilosadas estructuras partidistas de la izquierda tradicional. Superación no sólo en la concepción más programática, sino también en los métodos de inserción. ${ }^{22}$

orienta a privilegiar espacios de compactación del consenso que impulsan las clases dominantes en momentos de ofensiva, de agresividad y de mayor control sobre el pueblo." Elecciones de 1990..., op. cit.

${ }^{22}$ A excepción de 1978, Pueblo Unido ha confundido la dimensiónen la cual debe ubicarse el contexto electoral. Todo proceso electoral supone una prueba de ejercicio político para 


\section{SECUENCIG}

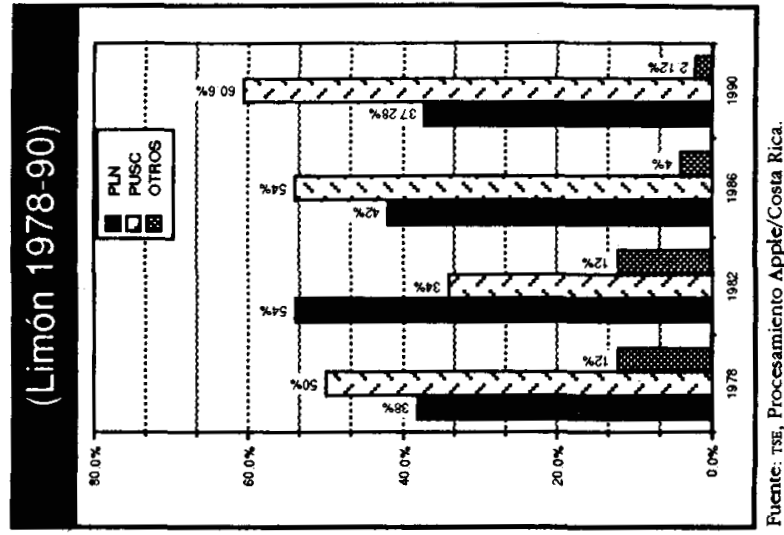

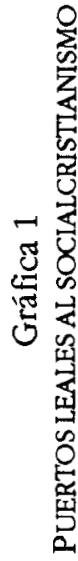
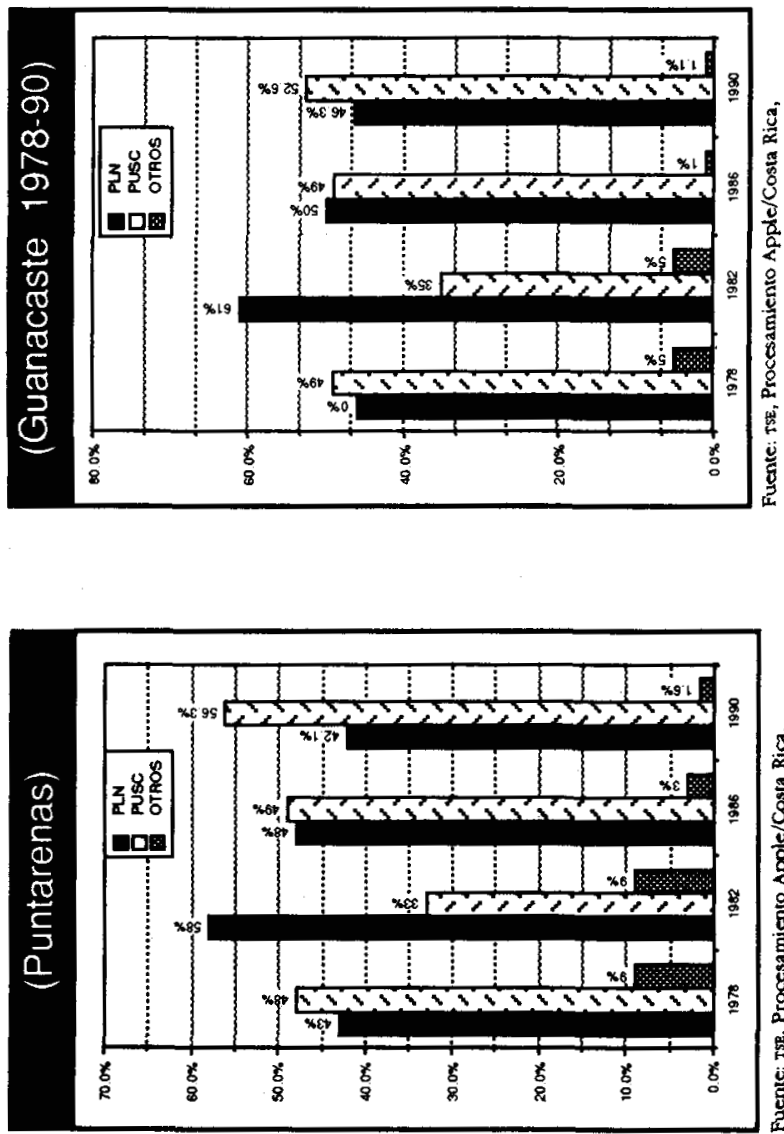

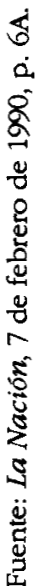


Gráfica 2

COMPORTAMIENTO DEL VOTO COMUNISTA

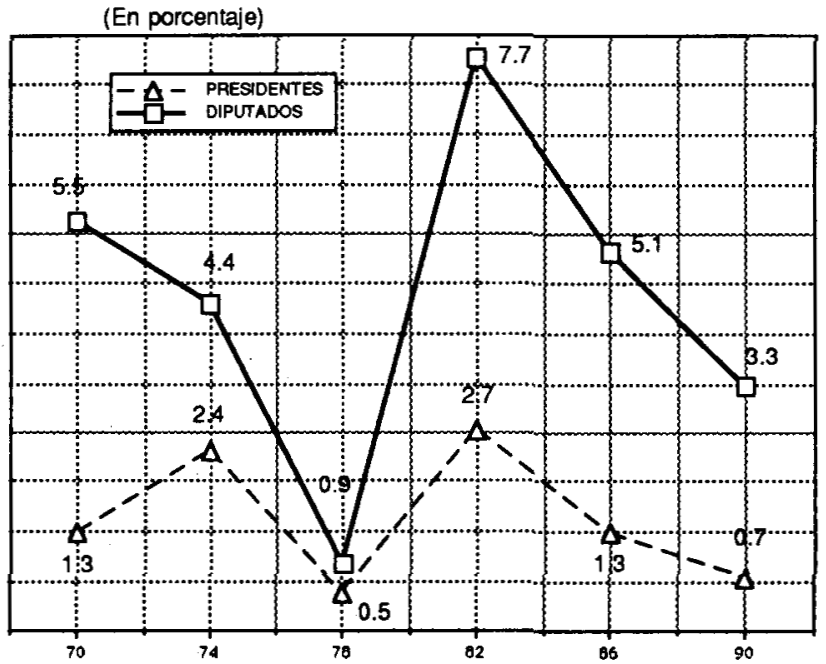

Fuente: TSE, Procesamiento Apple/Costa Rica.

\section{CONSIDERACIONES FINALES}

Si la soberanía popular descansa exclusivamente, según el discurso del bipartidismo, en la pureza del sufragio, aspecto que se pone en duda en las actuales condiciones por todo lo anteriormente señalado, lo que debemos preguntarnos entonces es ¿sobre qué bases se articula una democracia que se legitima gracias a los signos externos del "marketing elec-

demostrar el avance organizativo; locierto ha sido lo contrario: en 1970 la junta electoral aportó un $5.5 \%$ para diputados y $1.3 \%$ para presidente; cuatro años después el descenso comienza a tener ritmos más acentuados y, para 1978, año en que participa por primera vez la coalición Pueblo Unidoel respaldoelectoral fue de $0.5 \%$ para presidente y de $0.9 \%$ votos para diputados. Así tenemos que, de acuerdo a los datos del Tribunal Supremo de Elecciones (TSE), "en la consulta de $19827.7 \%$ de los electores votó por sus diputados; en 1986 el número bajó a $5.1 \%$ y en las de este año pasó a 3.3\%". La Nación, 6 de febrero de 1990, p. 11. toral" y no necesariamente en la discusión de propuestas programáticas?

Si la campaña electoral transfiere ciertos contenidos de "fiesta cívica", ¿por qué entonces en la redefinición del Estado se excluye al pueblo?

El 4 de febrero de 1990 no se definió el futuro de Costa Rica, todo lo contrario, una vez más surge a la luz pública el angostamiento de la democracia liberal burguesa, al consolidar un "monopartidismo bicéfalo", como atinadamente lo llama Daniel Camacho, que deja fuera de lugar a nuevas opciones.

Otros rasgos del pasado torneo electoral nos permiten ver el desgaste de un proyecto socialdemócrata con orientaciones más rítmicas hacia una concepción neoliberal. Por lo que hace a la "ortodoxia marxista" y otras nuevas expresiones, la evidencia histórica es más que contundente. Son, ciertamente, la tercera opciôn, pero cada proceso electoral les fija más su endeble y pírrica presencia 
Gráfica 3

VOTACION PARA DIPUTADOS DE LA IZQUIERDA

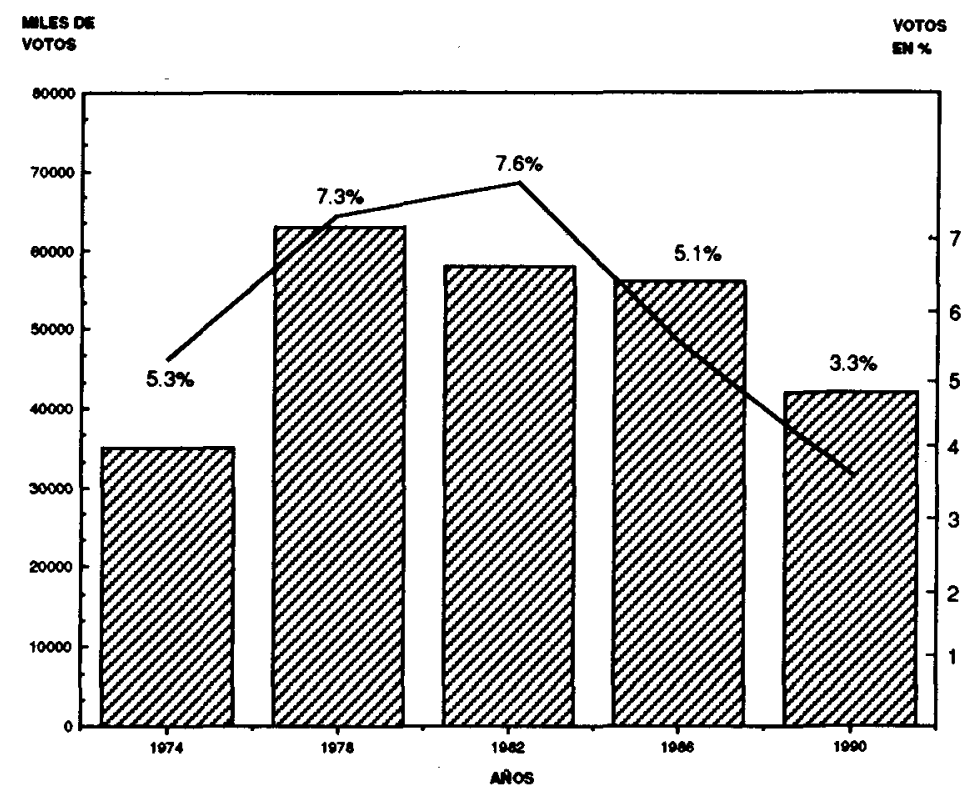

Las votaciones son obtenidas en 1974 por el PASO y el PSC, en 1978, 1982 y 1990 por Pueblo Unido y en 1986 por Alianza Popular y Pueblo Unido.

orgánica y, más que eso, su escasa capacidad creativa para dar nuevas lecturas a un tejido social complejo por sus formas de articulación.

En la lógica de los "signos externos" votar por el PUSC era votar por la "ampliación de la democracia", rescatar la sociedad civil, posibilitar la soberanía popular mediante el ejercicio del sufragio; votar por otras opciones que no fuese Liberación Nacional, era estar contra la historia. El resultado del último proceso electoral es, sin lugar a dudas, el clamor de una masa que reclama nuevos espàcios en el ejercicio del poder y en la configuración del Estado, pero de manera metafórica, porque el nuevo concepto de Estado y el carácter de la sociedad civil ha prefijado con más antelación su verdadero carácter. El triunfo de Calderón Fournier es el ejercicio del voto para ampliar un cierto tipo de democracia-antidemocrática que consolida al bipartidismo.

La paz como categoría absolutizadora, la política económica de estabilidad y crecimiento, aspectos que caracterizaron los últimos ocho años de gobierno del PLN, tuvieron que ceder al discurso socialcristiano, cargado de una fuerte dosis de populismo, de denuncias de comupción y de alternancia en el poder.

El péndulo de la historia acorta sus ritmos y la sociedad civil, por lo que hace a Costa Rica, fija más sus líneas hacia la derecha en los marcos de los organismos financieros internacionales y dentro de la lógica que el imperialismo norteamericano ha decidido para el conjunto de la región centroamericana. 